\title{
MRKH SYNDROME: KEY ROLE OF COUNSELING
}

\author{
K. A. Yelikar ${ }^{1}$, A. D. Yelikar², S. S. Deshpande ${ }^{3}$ J. P. Wakpanjar, S. Pagare ${ }^{5}$
}

\section{HOW TO CITE THIS ARTICLE:}

K. A. Yelikar, A. D. Yelikar, S. S. Deshpande, J. P. Wakpanjar, S. Pagare. "MRKH Syndrome: Key Role of Counseling". Journal of Evolution of Medical and Dental Sciences 2014; Vol. 3, Issue 23, June 09;

Page: 6516-6520, DOI: 10.14260/jemds/2014/2775

\begin{abstract}
Mayer-Rokitansky-Kuster-Hauser (MRKH) syndrome is a congenital malformation of vertical fusion defect of mullerian system characterized by an absence of the vagina associated with a variable abnormality of the uterus and the urinary tract but functional ovaries. We are reporting 21 years primary ammenorrhea case. Clinically it was diagnosed as Mayer-Rokitansky-Kuster-Hauser (MRKH) syndrome, which was confirmed, by sonography and laparoscopy. She was treated with Mcindoe technique. Counseling before the surgery was done followed by rehabilitation as both of them play pivotal role in such treatment. Counseling and rehabilitation after the vaginoplasty is equally important.
\end{abstract}

KEYWORDS: MRKH, counseling.

INTRODUCTION: MRKH may be isolated (type I) but it is more frequently associated with renal, vertebral and to a lesser extent, auditory and cardiac defects (MRKH type II or MURCS association). The first sign of MRKH syndrome is primary amenorrhea in young women presenting otherwise with normal development of secondary sexual characteristics and normal external genitalia, with normal and functional ovaries, and karyotype 46, XX without visible chromosomal anomaly. This condition causes the vagina and uterus to be underdeveloped or absent.(1) Surgical correction of the vaginal anomaly permits normal sexual function although women with such condition are usually unable to carry a pregnancy, they may be able to have children through surrogacy.

Incidence is about 1 in 4000 to 5000 female births and is a common cause of primary amenorrhea. ${ }^{(2)}$

Treatment of the MRKH syndrome consists of creating a neovagina, which can be offered to patients when they are emotionally mature and ready to commence sexual activity. Treatment may either be surgical or non-surgical, but the chosen method needs to be tailored to the individual needs, motivation of the patients, and the options available.(3)

We report our experience in the management of patient with congenital absence of the vagina due to the MRKH syndrome.

CASE: XYZ was a 21years-old student, from a rural background referred to our unit with complaints of primary amenorrhea with no associated symptoms. The patient had no significant past medical and family history.

On examination patient had well developed secondary sexual characters. Vaginal examination showed blind pouch of vagina. An abdominal ultrasound scan showed normal ovaries and kidney, the uterus was not demonstrated. She was subjected to diagnostic laparoscopy, which confirmed the absence of uterus and other mullerian structures.

The parents were explained about the anomaly and the inability of the patient to menstruate or to bear children. Patient reported after one month to hospital with a proposal of marriage to a man who was demanding a dowry with the well planned cruel intenion to use that money for his benefits 
and and then divorce the girl. After 3-4 sittings of counselling and persuading parents that such hard steps of marrying such a man would put girl's life at stake.

We asked them to reconsider their decision and complete the girls education. Such condition makes girls more vulnerable in Indian society. once the marriage is fixed then the vaginoplasty could be done so that it becomes easy for the maintainence of patency of the vagina due to coital function.The girl completed her professional education in teaching and reported with her fiance who had two children from his first wife.

The would be husband was counseled on the nature of the anomaly and the options available as well as the prospects of child bearing. He was fully convinced and still ready to marry her as he found a prospective mother in her for her orphan children.

She was posted for McIndoe vaginoplasty using a split skin graft followed by mould made of dental wax in neovagina.After three months the girl married and reported after two weeks happily because her vagina was functioning well.

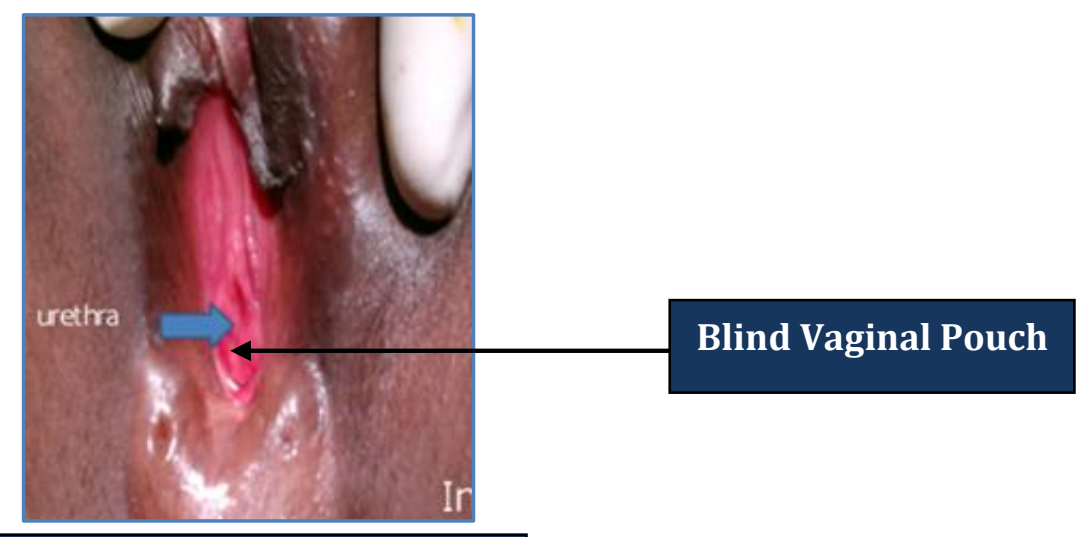

\section{Fig. 1: Blind vaginal pouch}

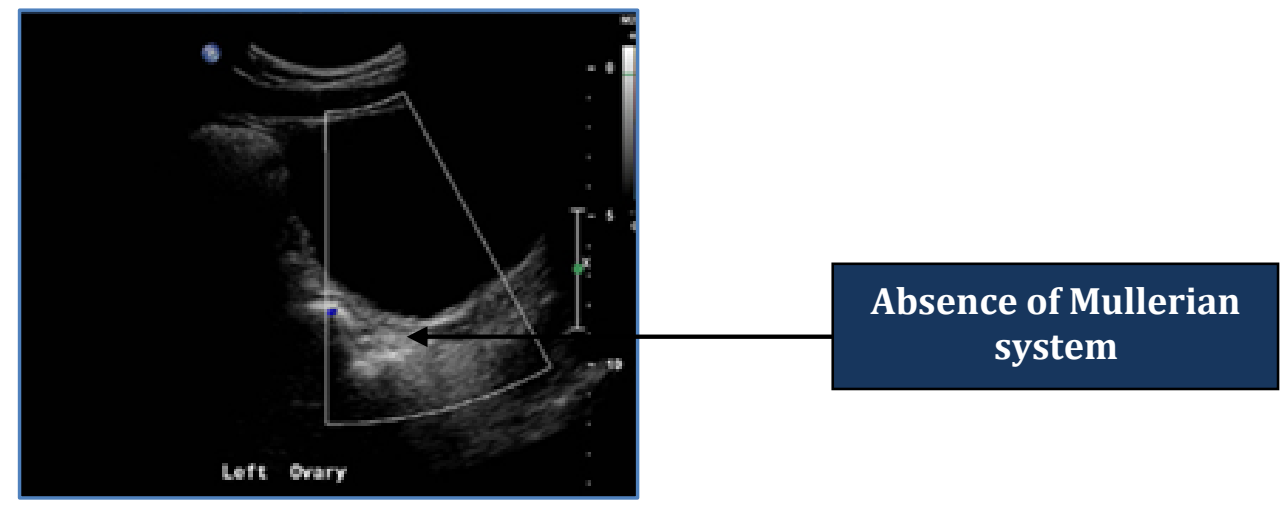

Fig. 2: USG showing absence of uterus 


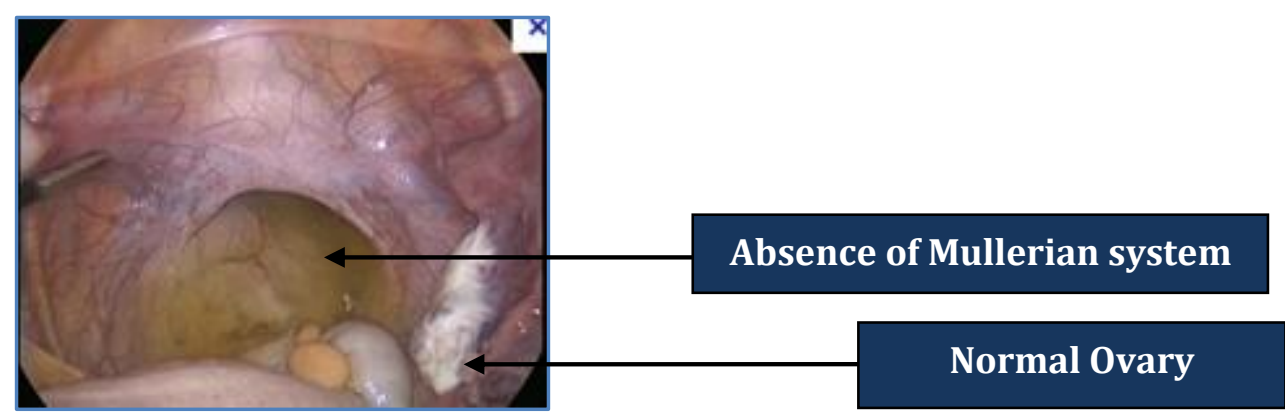

Fig. 3: laparoscopy confirms absence of uterus with normal ovaries

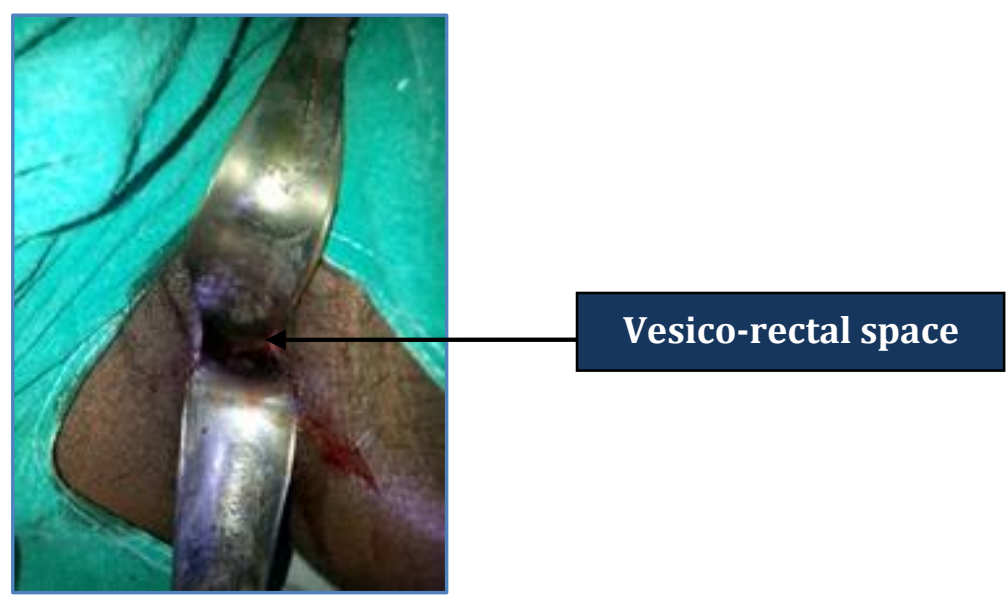

Fig. 4: dissection of vesico- rectal space

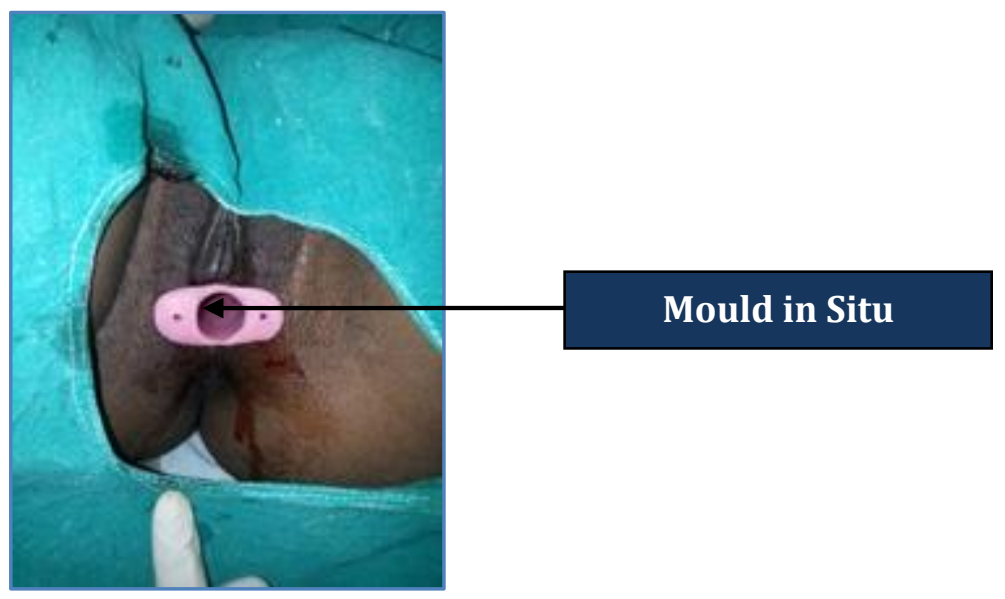

\section{Fig. 5: Post op 7thday} with mould in situ 


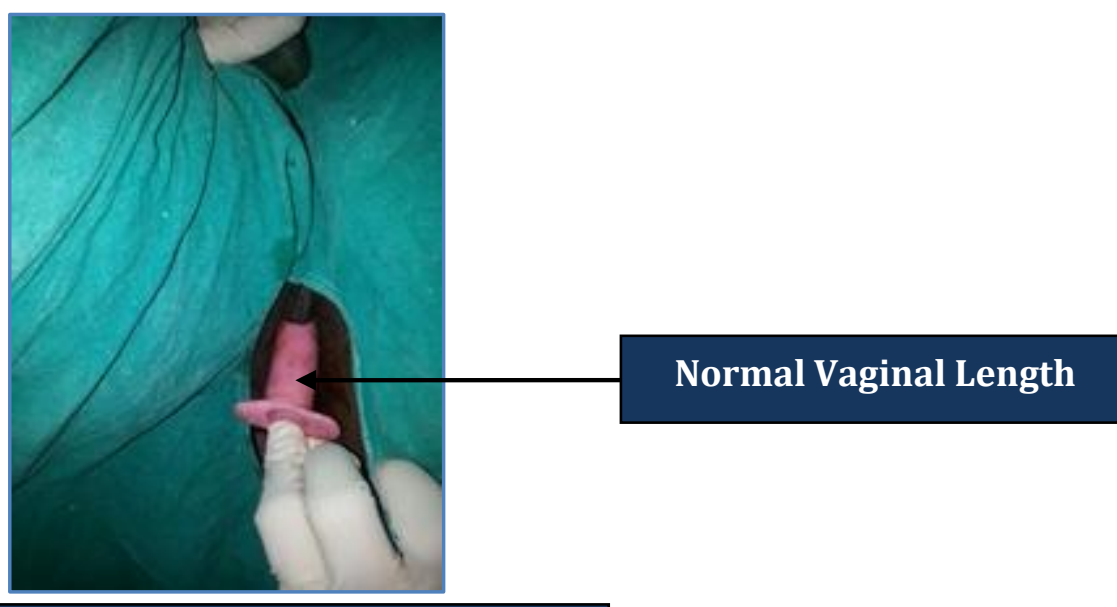

\section{Fig. 6: Mould showing normal length}

DISCUSSION: Diagnosis of the MRKH syndrome patients is usually delayed until adolescence. Primary ammenorrhoea is the reason that leads the patients to the clinicians. (4) These patients suffer severe distortion of the body image, anxiety, depression, interpersonal sensitivity, and face a lot of psychological distress at diagnosis.(3) In our environment, where gender role and identity are very crucial, these patients and families face difficult times hence awareness among people needs to be increased about its surgical treatment.

Although there is no consensus on which technique to use, the McIndoe has been the preferred method for many clinicians. We choose to use it because of its low complication rate and relative simplicity. In addition, the McIndoe technique does not require a transabdominal approach, which mitigates surgical risk.(5) Reconstructing the vagina using skin graft is non-invasive technique, cheap and can be afforded by poor with less risk of stenosis.

CONCLUSION: Many surgeons have practiced various options of surgical treatment. Professional counseling of the patient and her parents should begin shortly after the abnormality is recognized. However, the physician can help by introducing the subject with appropriate comments at diagnosis; indeed, failing to address the impact of this diagnosis immediately can contribute to subsequent poor psychological adaptation.

Early referral for counseling is essential for all of these patients to help them deal with issues of inadequacy and motherhood. Low self-esteem and alterations in anatomic development can threaten the patient's self-image and feeling of femininity. Even if the patient seems well adjusted, she should still be given the opportunity over the long term to discuss any concerns with a professional sex therapist. In both medical treatment and counseling, the concept that sexual identity is more comprehensive than sexual functioning should be emphasized. Vaginal reconstruction using the skin graft has given a good, immediate outcome in this report. It is cheap and affordable by poor people. Patient can have active sexual life. 


\section{REFERENCES:}

1. Karine Morcel, Laure Camborieux. Mayer-Rokitansky-Küster-Hauser (MRKH) syndrome. Orphanet J Rare Dis. 2007; 2: 13.

2. Viral N Shah, Parth J Ganatra, Rajni Parikh, Panna Kamdar, Seema Baxi, Nishit Shah. Coexistence of gonadal dysgenesis and Mayer-Rokitansky-Kuster-Hauser syndrome in 46, XX female: A case report and review of literature.ijem.2013; 17(7): 274-277

3. A. Mungadi, Y. Ahmad, G. H. Yunusa, N. P. Agwu, Mayer-Rokitansky-Kuster-Hauser Syndrome: Surgical Management of Two Cases. J Surg Tech Case Rep. 2010 Jan-Jun; 2 (1): 39-43.

4. S Sharma, N Aggarwal, S Kumar, A Negi, Jr Azad, S. Sood. Atypical Mayer-Rokitansky-KusterHauser Syndrome with scoliosis, renal \& anorectal malformation - Case report. Ind J Radiol Imag 2006; 16: 4: 809-812.

5. Ercan Bastu, Suleyman Engin Akhan, Mehmet Firat Mutlu, treatment of vaginal agenesis using a modified McIndoe technique: Long-term follow-up of 23 patients and a literature review. Can J Plast Surg. 2012 Winter; 20 (4): 241-244,

\section{AUTHORS:}

1. K. A. Yelikar

2. A. D. Yelikar

3. S. S. Deshpande

4. J. P. Wakpanjar

5. S. Pagare

\section{PARTICULARS OF CONTRIBUTORS:}

1. Professor and HOD, Department of Obstetrics and Gynaecology, Government Medical College, Aurangabad.

2. Honanary Professor, Department of Plastic Surgery, Government Medical College, Aurangabad.

3. Associate Professor, Department of Plastic Surgery, Government Medical College, Aurangabad.

4. Assistant Professor, Department of Plastic Surgery, Government Medical College, Aurangabad.
5. Assistant Professor, Department of Plastic Surgery, Government Medical College, Aurangabad.

\section{NAME ADDRESS EMAIL ID OF THE CORRESPONDING AUTHOR:}

Dr. Kanan Yelikar, \#12, Ashwini Hospital, Samarth Nagar, Aurangabad-4310051, Maharashtra.

E-mail: drkanany@yahoo.co.in

Date of Submission: 21/05/2014. Date of Peer Review: 22/05/2014.

Date of Acceptance: 31/05/2014.

Date of Publishing: 09/06/2014. 